\title{
PRODUÇÃO E CARACTERÍSTICAS BIOQUÍMICAS DE PROTEASES PRODUZIDAS POR ASPERGILLUS NIGER EM RESPOSTA A DIFERENTES RESÍDUOS AGROINDUSTRIAIS
}

\author{
R. J. S. DE CASTRO ${ }^{1}$, T. G. NISHIDE ${ }^{1}$, H. H. SATO ${ }^{1}$ \\ ${ }^{1}$ Universidade Estadual de Campinas, Faculdade de Engenharia de Alimentos, Departamento de \\ Ciência de Alimentos \\ E-mail para contato: ruannjanser@hotmail.com
}

RESUMO - O presente trabalho relata a produção e estudo de algumas características bioquímicas de proteases produzidas por Aspergillus niger LBA 02 em fermentação em estado sólido utilizando-se resíduos agroindustriais. A maior produção de proteases foi observada em farelo de trigo, atingindo 186,4 $\mathrm{U}_{\mathrm{g}} \mathrm{g}^{-1}$ após $96 \mathrm{~h}$ de fermentação. As proteases produzidas em farelo de trigo (PFT), farelo de soja (PFS) e farelo de algodão (PFA) apresentaram atividade ótima nas faixas de $\mathrm{pH} 3,0-5,0$ a $45-55,0^{\circ} \mathrm{C}$ e mostraram-se estáveis na faixa de $\mathrm{pH} 2,5-5,0$ após $1 \mathrm{~h}$ de tratamento a $40,0-50,0^{\circ} \mathrm{C}$. As proteases apresentaram maior especificidade pelo substrato hemoglobina de sangue bovino, atingindo atividades relativas de 183,84, 147,06 e 186,81\% para PFT, PFS e PFA, respectivamente, considerando-se a atividade para o substrato caseína como padrão (100,0\%). A preparação enzimática PFT apresentou maior relação entre a atividade coagulante do leite e a atividade proteolítica $(15,24)$, seguida das enzimas PFA $(6,28)$ e PFS $(0,38)$.

\section{INTRODUÇÃO}

As proteases constituem um dos mais importantes grupos de enzimas produzidos comercialmente e têm aplicação em diferentes indústrias, como de alimentos, têxtil, farmacêutica e de detergentes (Kanekar et al., 2002). Proteases respondem por mais de $60,0 \%$ de todo o mercado mundial de enzimas (Oskouie et al., 2008), sendo 40,0\% desse total, de origem microbiana (Rao et al., 1998).

As enzimas microbianas podem ser obtidas tanto por processo submerso, quanto por fermentação em estado sólido (FES). No caso de cultivo de fungos filamentosos, a FES apresenta diversas vantagens em relação à fermentação submersa, como: condições de cultivo mais parecidas com o habitat natural dos fungos, facilitando o crescimento e a secreção de enzimas, menores custos e maior concentração dos produtos após a extração (Pandey, 2003). Este processo desperta maior interesse econômico em regiões, como o Brasil, com abundância em biomassa e resíduos agroindustriais de baixo custo, como a soja, o trigo e o algodão que atingiram juntos no ano de 2012, uma produção nacional de aproximadamente 85,0 milhões de toneladas (FAO, 2014). A utilização de resíduos, obtidos a partir do processamento destes insumos, como substratos para o desenvolvimento de processos biotecnológicos, como a produção de enzimas por fermentação em estado sólido é um exemplo promissor da obtenção de biomoléculas de alto valor agregado a partir de substratos de baixo custo. 
Além dos aspectos de produção, a caracterização bioquímica de enzimas é importante para avaliar o seu potencial biotecnológico. $\mathrm{O}$ estudo de proteases com diferentes propriedades, tais como especificidade de substrato, termoestabilidade, atividade em amplas faixas de $\mathrm{pH}$ e temperatura, são importantes para o êxito da aplicação destas enzimas na indústria.

Estudos anteriores mostraram que a expressão e secreção de diferentes conjuntos de proteases e outras enzimas, bem como as suas propriedades bioquímicas, podem ser reguladas pelo tipo de substrato utilizado como fonte de carbono e nitrogênio (Speranza et al., 2011; Farnell et al., 2012). Neste contexto, os principais objetivos do presente estudo foram avaliar a produção da protease por $A$. niger LBA 02 em fermentação em estado sólido utilizando resíduos agroindustriais como substratos e estudar algumas propriedades bioquímicas das proteases produzidas em resposta a cada resíduo, incluindo $\mathrm{pH}$ e temperatura ótimos para atividade e estabilidade, especificidade de substrato e atividade de coagulação do leite.

\section{MATERIAL E MÉTODOS}

\subsection{Micro-organismo e resíduos agroindustriais empregados}

O micro-organismo empregado nesse trabalho foi a linhagem de A. niger LBA 02 da coleção de culturas do Laboratório de Bioquímica de Alimentos do Departamento de Ciência de Alimentos da Faculdade de Engenharia de Alimentos da Universidade Estadual de Campinas. Foram utilizados como substratos para produção de proteases por fermentação em estado sólido: farelo de soja, farelo de algodão e farelo de trigo, gentilmente cedidos pela Bunge Alimentos S.A.

\subsection{Produção de proteases de $A$. niger LBA 02 por fermentação em estado sólido utilizando-se diferentes substratos e obtenção dos extratos enzimáticos}

As fermentações foram realizadas em frascos Erlenmeyers de $500 \mathrm{~mL}$ contendo $40 \mathrm{~g}$ de meio de cultivo de farelo de soja, farelo de algodão ou farelo de trigo umedecidos com água destilada até $50 \%$ de umidade. Os frascos foram esterilizados em autoclave a $121^{\circ} \mathrm{C}$ por 15 minutos, inoculados com suspensão de esporos $\left(10^{7}\right.$ esp. $\left.{ }^{-1}\right)$ e incubados a $30,0^{\circ} \mathrm{C}$ durante $96 \mathrm{~h}$ com coleta de amostras a cada $24 \mathrm{~h}$; condições previamente definidas como adequadas para a produção de proteases pela linhagem de A. niger LBA 02. A extração das proteases foi realizada pela homogeneização do meio fermentado com $150 \mathrm{~mL}$ de água destilada, incubação por 60 minutos a $30,0^{\circ} \mathrm{C}$ e posterior filtração.

\subsection{Determinação das condições de pH e temperatura ótimos de atividade e de estabilidade da protease de $A$. niger LBA 02 por planejamento experimental}

O software Statistica ${ }^{\circledR} 10.0$ da Statsoft, Inc. (Tulsa, Oklahoma, EUA) foi utilizado no delineamento experimental, análise de dados e obtenção dos modelos. A fim de avaliar os efeitos e verificar a interação entre as duas variáveis estudadas, foi realizado um Delineamento Composto Central Rotacional (DCCR) com 11 ensaios. As variáveis e os níveis estudados no DCCR estão apresentados na Tabela 1. Uma equação de segunda ordem foi utilizada para definição dos modelos, como mostrado a seguir: 


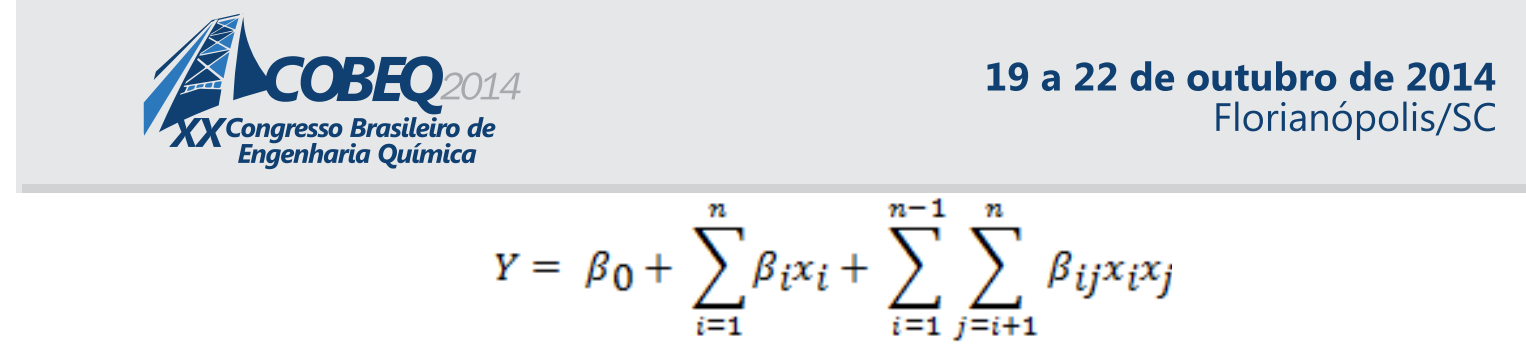

onde $Y$ representa a resposta estimada pelo modelo, $i$ e $j$ correspondem à variação de 1 ao número de variáveis $(n), \beta_{0}$ é a média, $\beta i$ e $\beta i j$ representam os coeficientes lineares e quadráticos, respectivamente; $x i$ e $x j$ são as variáveis independentes codificadas. O coeficiente de correlação múltipla $\left(R^{2}\right)$ e o teste de Fisher (análise de variância-ANOVA) foram utilizados para verificar a adequação estatística dos modelos codificados aos pontos reais.

\subsection{Determinação da atividade de protease}

A atividade proteolítica utilizando azocaseína como substrato foi determinada segundo a metodologia de Charney e Tomarelli (1947) e descrito por Castro e Sato (2013). Uma unidade de atividade proteolítica foi definida como a quantidade de enzima que produz uma diferença de 0,01 na absorbância a $428 \mathrm{~nm}$ por minuto de reação entre o branco reacional e a amostra nas condições do ensaio.

\subsection{Especificidade de substrato}

As proteases produzidas por A. niger LBA 02 em farelo de trigo, farelo de soja e farelo de algodão foram avaliados quanto à especificidade de substrato utilizando caseína, proteínas do soro de leite, proteína concentrada de soja, proteína isolada de soja, hemoglobina de sangue bovino, gelatina e albumina de ovo. A concentração de cada preparação enzimática foi ajustada para 20,0 U por $\mathrm{mL}$ de mistura reacional, de acordo com a atividade proteolítica, previamente determinada. Os substratos foram dissolvidos em tampão de acetato $50 \mathrm{mM}(\mathrm{pH} 5,0)$ na concentração de $10 \mathrm{mg} \mathrm{mL}^{-1}$. A mistura reacional contendo $1,0 \mathrm{~mL}$ de solução de cada substrato e $1,0 \mathrm{~mL}$ da solução enzimática foi incubada a $50,0^{\circ} \mathrm{C}$ durante $60 \mathrm{~min}$. A reação foi paralisada pela adição de $1,0 \mathrm{~mL}$ de TCA $(10,0 \%)$. Os tubos de ensaio foram centrifugados a $17.000 \times \mathrm{g}$ durante 15 min a $5^{\circ} \mathrm{C}$ e a absorbância do sobrenadante foi medida a $280 \mathrm{~nm}$. Os resultados foram expressos como atividade relativa (\%) utilizando o substrato de caseína como padrão (100,0\%).

\subsection{Atividade coagulante do leite}

A determinação da atividade coagulante do leite foi realizada de acordo com o método descrito por Ahmed et al., (2009). Uma avaliação comparativa foi realizada utilizando diferentes preparações de proteases comerciais. Uma unidade de atividade coagulante do leite foi definida como a quantidade de enzima necessária para coagular $10 \mathrm{~mL}$ de substrato em $40 \mathrm{~min}$, como mostrado na equação abaixo:

$\operatorname{MCA}\left(\mathrm{U} \mathrm{mL}^{-1}\right)=(2400 /$ tempo de coagulação $(\mathrm{s})) \times$ fator de diluição.

\section{RESULTADOS E DISCUSSÃO}

Para os substratos avaliados, os maiores valores de atividade proteolítica foram observados a partir de $48 \mathrm{~h}$ de fermentação. A maior produção de proteases por A. niger LBA 02 foi detectada quando o farelo de trigo foi utilizado como substrato após $96 \mathrm{~h}$ de fermentação, atingindo $186,4 \mathrm{U} \mathrm{g}^{-1}$. Já para os substratos farelo de algodão e farelo de soja, os maiores valores de atividade obtidos foram $152,4 \mathrm{U} \mathrm{g}^{-1}$ e $118,8 \mathrm{U} \mathrm{g}^{-1}$, após 48 e 96h de fermentação, respectivamente (Tabela 1). 
Tabela 1 - Produção de protease por A. niger LBA 02 em fermentação em estado sólido utilizando diferentes substratos

\begin{tabular}{cccc}
\hline \multirow{2}{*}{ Tempo de fermentação $(\mathbf{h})$} & \multicolumn{3}{c}{ Atividade proteolítica $\left(\mathbf{U ~ g}^{\mathbf{- 1}}\right)$} \\
\cline { 2 - 4 } & Farelo de trigo & Farelo de soja & Farelo de algodão \\
\hline $\mathbf{2 4}$ & $13,4 \pm 0,48$ & $20,7 \pm 0,41$ & $16,6 \pm 0,52$ \\
$\mathbf{4 8}$ & $81,5 \pm 1,21$ & $152,4 \pm 3,14$ & $110,3 \pm 3,57$ \\
$\mathbf{7 2}$ & $176,2 \pm 6,52$ & $138,0 \pm 1,49$ & $111,7 \pm 4,21$ \\
$\mathbf{9 6}$ & $186,4 \pm 1,70$ & $94,0 \pm 3,94$ & $118,8 \pm 0,92$ \\
\hline
\end{tabular}

Os extratos brutos de proteases produzidos em farelo de trigo (PFT), farelo de soja (PFS) e farelo de algodão (PFA) foram caracterizados bioquimicamente. A Tabela 2 mostra a matriz do DCCR com as variáveis independentes $(\mathrm{pH}$ e temperatura) e os resultados para atividade e estabilidade das proteases de A. niger LBA 02.

Tabela 2 - Matriz do DCCR $2^{2}$ com as variáveis codificadas, reais e respostas para determinação das condições de $\mathrm{pH}$ e temperatura ótimos de atividade e estabilidade das proteases de A. niger LBA 02 produzidas em farelo de trigo (PFT), farelo de soja (PFS) e farelo de algodão (PFA)

\begin{tabular}{cccccc}
\hline \multicolumn{5}{c}{ pH e temperatura ótima de atividade } \\
\hline Ensaios & $\mathrm{x}_{1} / \mathrm{pH}$ & $\mathrm{x}_{2} /$ Temperatura $\left({ }^{\circ} \mathrm{C}\right)$ & $\mathrm{PFT}\left(\mathrm{U} \mathrm{g}^{-1}\right)$ & $\mathrm{PFS}\left(\mathrm{U} \mathrm{g}^{-1}\right)$ & \left.${\mathrm{PFA}\left(\mathrm{U} \mathrm{g}^{-1}\right)}^{-1}\right)$ \\
\hline 1 & $-1,0(2,73)$ & $-1,0(39,4)$ & $143,83 \pm 1,70$ & $44,12 \pm 0,51$ & $64,95 \pm 0,56$ \\
2 & $+1,0(6,27)$ & $-1,0(39,4)$ & $23,92 \pm 0,67$ & $23,23 \pm 0,69$ & $12,20 \pm 0,73$ \\
3 & $-1,0(2,73)$ & $+1,0(60,6)$ & $148,03 \pm 1,36$ & $41,63 \pm 0,33$ & $49,37 \pm 1,56$ \\
4 & $+1,0(6,27)$ & $+1,0(60,6)$ & $26,95 \pm 0,13$ & $25,38 \pm 1,33$ & $17,92 \pm 0,53$ \\
5 & $-1,41(2,00)$ & $0,0(50,0)$ & $163,35 \pm 10,10$ & $77,12 \pm 0,78$ & $83,80 \pm 4,09$ \\
6 & $+1,41(7,00)$ & $0,0(50,0)$ & $12,95 \pm 0,13$ & $13,72 \pm 1,32$ & $10,33 \pm 1,50$ \\
7 & $0,0(4,5)$ & $-1,41(35,0)$ & $120,58 \pm 2,58$ & $56,92 \pm 1,48$ & $66,92 \pm 1,27$ \\
8 & $0,0(4,5)$ & $+1,41(65,0)$ & $81,02 \pm 2,90$ & $68,40 \pm 0,93$ & $60,28 \pm 2,19$ \\
9 & $0,0(4,5)$ & $0,0(50,0)$ & $149,93 \pm 2,33$ & $102,55 \pm 2,65$ & $104,60 \pm 2,38$ \\
10 & $0,0(4,5)$ & $0,0(50,0)$ & $148,45 \pm 1,98$ & $102,28 \pm 0,90$ & $107,65 \pm 1,23$ \\
11 & $0,0(4,5)$ & $0,0(50,0)$ & $145,75 \pm 5,24$ & $101,08 \pm 2,42$ & $106,83 \pm 0,85$ \\
\hline \multicolumn{5}{c}{ pH e temperatura de estabilidade enzimática } & \\
\hline Ensaios & $\mathrm{x}_{1} / \mathrm{pH}$ & $\mathrm{x}_{2} / \mathrm{Temperatura}\left({ }^{\circ} \mathrm{C}\right)$ & $\mathrm{PFT}(\%)$ & $\mathrm{PFS}(\%)$ & $\mathrm{PFA}(\%)$ \\
\hline 1 & $-1,0(2,73)$ & $-1,0(39,4)$ & $63,20 \pm 0,33$ & $73,17 \pm 3,42$ & $79,02 \pm 2,89$ \\
2 & $+1,0(6,27)$ & $-1,0(39,4)$ & $11,99 \pm 4,33$ & $35,92 \pm 6,21$ & $12,01 \pm 0,96$ \\
3 & $-1,0(2,73)$ & $+1,0(60,6)$ & $25,58 \pm 0,48$ & $31,58 \pm 2,07$ & $1,17 \pm 0,57$ \\
4 & $+1,0(6,27)$ & $+1,0(60,6)$ & $1,43 \pm 0,80$ & $8,27 \pm 1,00$ & $2,78 \pm 1,32$ \\
5 & $-1,41(2,00)$ & $0,0(50,0)$ & $56,31 \pm 1,26$ & $46,51 \pm 6,42$ & $74,75 \pm 3,89$ \\
6 & $+1,41(7,00)$ & $0,0(50,0)$ & $2,42 \pm 3,62$ & $4,54 \pm 0,15$ & $4,61 \pm 1,17$ \\
7 & $0,0(4,5)$ & $-1,41(35,0)$ & $62,86 \pm 1,59$ & $71,13 \pm 5,96$ & $80,07 \pm 0,93$ \\
8 & $0,0(4,5)$ & $+1,41(65,0)$ & $4,81 \pm 1,65$ & $10,42 \pm 0,36$ & $2,76 \pm 1,87$ \\
9 & $0,0(4,5)$ & $0,0(50,0)$ & $97,48 \pm 2,09$ & $100,00 \pm 3,36$ & $96,32 \pm 1,30$ \\
10 & $0,0(4,5)$ & $0,0(50,0)$ & $98,73 \pm 2,28$ & $96,78 \pm 5,01$ & $95,57 \pm 1,02$ \\
11 & $0,0(4,5)$ & $0,0(50,0)$ & $100,00 \pm 0,86$ & $91,92 \pm 3,28$ & $100,00 \pm 2,27$ \\
\hline
\end{tabular}


No estudo das condições de $\mathrm{pH}$ e temperatura ótimos para atividade de protease, as preparações enzimáticas PFS e PFA apresentaram máxima atividade quando incubadas a $50,0^{\circ} \mathrm{C}$ e $\mathrm{pH}$

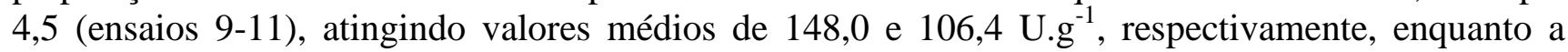
preparação enzimática PFT mostrou-se mais ativa quando incubada a 50,0 ${ }^{\circ} \mathrm{C}, \mathrm{pH} 2,0$ (ensaio 5), atingindo 163,3 U.g ${ }^{-1}$. Nos estudos das condições de estabilidade, as três preparações enzimáticas avaliadas apresentaram-se mais estáveis abaixo de $50,0^{\circ} \mathrm{C}$ e $\mathrm{pH} 4,5$ (ensaios 9-11) (Tabela 2).

As proteases PFT e PFS mostraram menor estabilidade em temperaturas acima de $60,0^{\circ} \mathrm{C}$ e na faixa de pH 6,0-7,0, atingindo atividades residuais de protease de 1,43\% (ensaio 4) e 4,54\% (ensaio 6), respectivamente. Para a preparação PFA, a atividade residual mínima de $1,17 \%$, foi observada quando a enzima foi incubada a $60,6^{\circ} \mathrm{C}$ e pH 2,73 (ensaio 3) (Tabela 2). A variabilidade limitada dos pontos centrais (ensaios 9-11) indicou boa reprodutibilidade dos dados experimentais (Tabela 2).

As equações, $R^{2}$, os valores de $F$ e $p$, assim como os testes de validação realizados sob as condições de $\mathrm{pH}$ e temperatura previstas pelos modelos para máxima atividade e estabilidade das proteases de $A$. niger LBA 02 estão apresentadas na Tabela 3.

Tabela 3 - Modelos, $R^{2}$, valores de $F$, $p$-valor e testes de validação realizados sob as condições de $\mathrm{pH}$ e temperatura previstas pelos modelos para máxima atividade e estabilidade das proteases de $A$. niger

LBA 02

\begin{tabular}{|c|c|c|c|c|c|c|c|c|}
\hline \multicolumn{9}{|c|}{ pH e temperatura ótima de atividade } \\
\hline \multicolumn{2}{|c|}{ Respostas } & \multicolumn{3}{|c|}{ Equações } & $\begin{array}{c}F- \\
\text { calculado }\end{array}$ & $\begin{array}{c}F \\
\text { tabelado }\end{array}$ & $R^{2}$ & $p$-valor \\
\hline \multicolumn{2}{|c|}{$\operatorname{PFT}\left(\mathrm{U} \mathrm{g}^{-1}\right)$} & \multicolumn{3}{|c|}{$Y=-460,68+60,50 \mathrm{pH}-10,28 \mathrm{pH}^{2}+22,36 \mathrm{~T}-0,23 \mathrm{~T}^{2}$} & 67,30 & 4,53 & 0,98 & $<0,001$ \\
\hline \multicolumn{2}{|c|}{$\operatorname{PFS}\left(\mathrm{U} \mathrm{g}^{-1}\right)$} & \multicolumn{3}{|c|}{$Y=-633,49+87,21 \mathrm{pH}-10,68 \mathrm{pH}^{2}+22,19 \mathrm{~T}-0,22 \mathrm{~T}^{2}$} & 11,97 & 4,53 & 0,89 & 0,005 \\
\hline \multicolumn{2}{|c|}{$\operatorname{PFA}\left(\mathrm{U} \mathrm{g}^{-1}\right)$} & \multicolumn{3}{|c|}{$Y=-627,29+85,94 \mathrm{pH}-11,02 \mathrm{pH}^{2}+23,03 \mathrm{~T}-0,23 \mathrm{~T}^{2}$} & 21,22 & 4,53 & 0,93 & 0,005 \\
\hline \multicolumn{9}{|c|}{ pH e temperatura de estabilidade } \\
\hline \multicolumn{2}{|c|}{ PFT $(\%)$} & \multicolumn{3}{|c|}{$Y=-684,14+75,49 \mathrm{pH}-11,58 \mathrm{pH}^{2}+27,02 \mathrm{~T}-0,30 \mathrm{~T}^{2}+0,36 \mathrm{pH} \times \mathrm{T}$} & 72,84 & 3,45 & 0,98 & $<0,001$ \\
\hline $\mathrm{PFS}$ & $\%)$ & \multicolumn{3}{|c|}{$Y=-589,94+90,36 \mathrm{pH}-10,98 \mathrm{pH}^{2}+21,90 \mathrm{~T}-0,24 \mathrm{~T}^{2}$} & 131,32 & 4,01 & 0,98 & $<0,001$ \\
\hline $\mathrm{PF} A$ & $(\%)$ & \multicolumn{3}{|c|}{$Y=-437,07+79,55 \mathrm{pH}-10,35 \mathrm{pH}^{2}+16,16 \mathrm{~T}-0,18 \mathrm{~T}^{2}+0,13 \mathrm{pH} \times \mathrm{T}$} & 23,97 & 3,45 & 0,96 & 0,002 \\
\hline \multicolumn{9}{|c|}{ Ensaios para validação } \\
\hline \multicolumn{4}{|c|}{ Atividade máxima de protease } & \multicolumn{2}{|c|}{ Resposta prevista $\left(\mathrm{U} \mathrm{g}^{-1}\right)$} & \multicolumn{3}{|c|}{ Resposta experimental $\left(\mathbf{U ~ g}^{-1}\right)$} \\
\hline PFT & \multicolumn{2}{|c|}{$\mathrm{pH} 3,0$} & Temperatura $48,7^{\circ} \mathrm{C}$ & 173,46 & \multicolumn{4}{|c|}{$181,20 \pm 13,72$} \\
\hline PFS & \multicolumn{2}{|c|}{$\mathrm{pH} 4,0$} & Temperatura $50,4^{\circ} \mathrm{C}$ & 103,97 & \multicolumn{4}{|c|}{$102,55 \pm 1,78$} \\
\hline PFA & \multicolumn{2}{|c|}{$\mathrm{pH} 4,0$} & Temperatura $49,5^{\circ} \mathrm{C}$ & 110,49 & \multicolumn{4}{|c|}{$106,36 \pm 4,58$} \\
\hline \multicolumn{4}{|c|}{ Estabilidade máxima da protease } & \multicolumn{2}{|c|}{ Resposta prevista } & Resposta e & xperim & ntal \\
\hline PFT & $\mathrm{pH}$ & $5-4,5$ & Temperatura: $45,0-50,0^{\circ} \mathrm{C}$ & $\geq 95,0 \% / \geq 170,5$ & $\mathrm{Jg}^{-1}$ & $01,3 \pm 1,55 \% /$ & $172,7=$ & $2,69 \mathrm{U} \mathrm{g}^{-1}$ \\
\hline PFS & $\mathrm{pH}$ & $5-4,5$ & Temperatura: $45,0-50,0^{\circ} \mathrm{C}$ & $\geq 95,0 \% / \geq 89,7$ & & $01,6 \pm 3,37 \%$ & $91,1 \pm$ & $07 \mathrm{Ug}^{-1}$ \\
\hline PFA & $\mathrm{pH}$ & $0-4,5$ & Temperatura: $40,0-50,0^{\circ} \mathrm{C}$ & $\geq 95,0 \% / \geq 109,1$ & $\mathrm{~J} \mathrm{~g}^{-1}$ & $02,8 \pm 2,37 \% /$ & $112,1=$ & $2,66 \mathrm{U} \mathrm{g}^{-1}$ \\
\hline
\end{tabular}


A análise de variância (ANOVA) revelou que os modelos foram capazes de explicar de 89$98 \%$ da variação total dos experimentos realizados. Os valores de $F$-calculado para as regressões foram superiores aos valores tabelados, refletindo a significância estatística dos modelos propostos. Os modelos foram validados experimentalmente, mediante a não observação de diferenças significativas entre os valores de atividade de protease previstos pelo modelo e experimentais em um intervalo de confiança de $95,0 \%$ (Tabela 3 ).

A análise das curvas de contorno indicou que as proteases das preparações foram mais ativas nas faixas de $\mathrm{pH}$ 2,0-5,0 e 45,0-55,0 ${ }^{\circ} \mathrm{C}$ (Figura 1). As preparações enzimáticas PFT e PFS apresentaram-se estáveis na faixa de $\mathrm{pH} 3,0-5,0$ após $1 \mathrm{~h}$ de incubação a $40,0-50,0^{\circ} \mathrm{C}$ enquanto a preparação PFA mostrou maior estabilidade na faixa de $\mathrm{pH} 2,0$ a 5,0 após $1 \mathrm{~h}$ a $40,0-50,0^{\circ} \mathrm{C}$, retendo atividade de protease superior a 64,0\% (Figura 2).
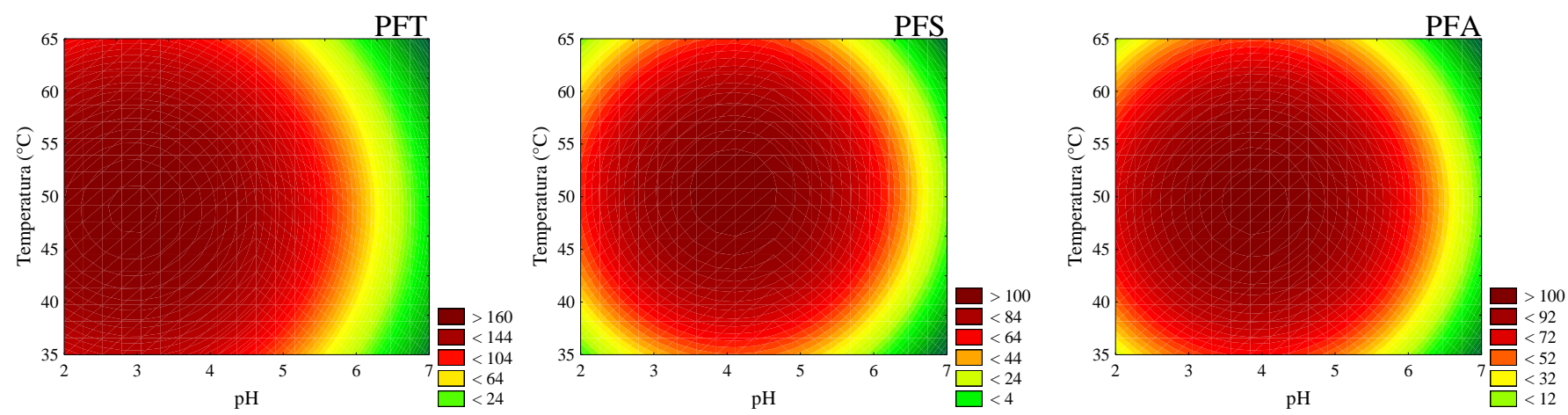

Figura 1 - Curvas de contorno para as atividades das proteases de A. niger LBA 02 produzidas farelo de trigo (PFT), farelo de soja (PFS) e farelo de algodão (PFA) em função do pH e da temperatura $\left({ }^{\circ} \mathrm{C}\right)$.
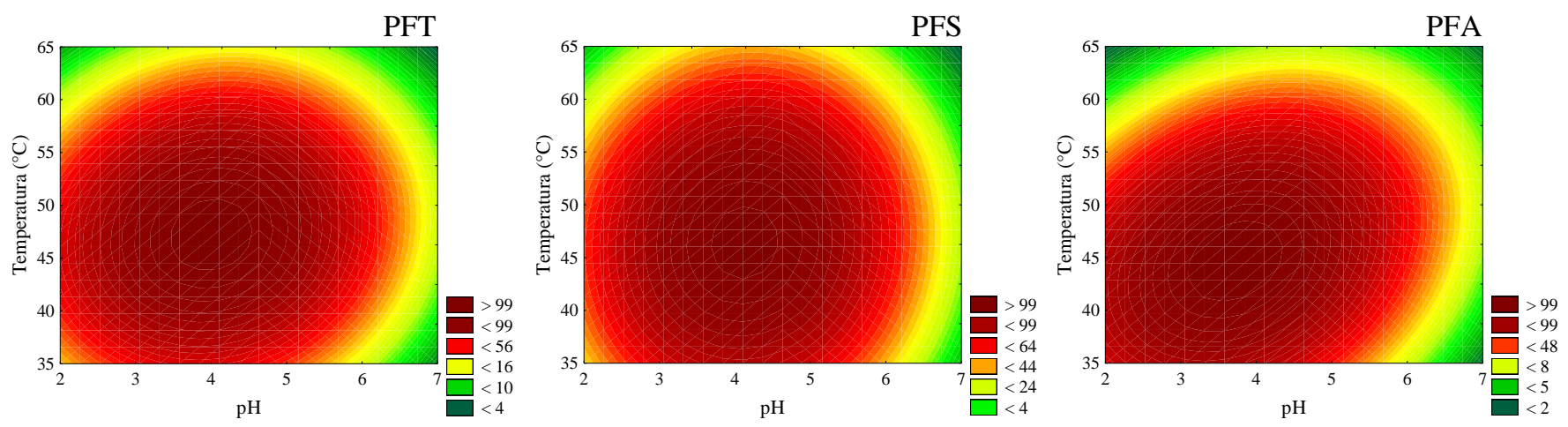

Figura 2 - Curvas de contorno para as atividades residuais das proteases de A. niger LBA 02 produzidas farelo de trigo (PFT), farelo de soja (PFS) e farelo de algodão (PFA) em função do $\mathrm{pH}$ e da temperatura $\left({ }^{\circ} \mathrm{C}\right)$ : estudo da estabilidade.

A atividade proteolítica das preparações enzimáticas de A. niger LBA 02 produzidas em diferentes resíduos agroindustriais foi avaliada utilizando-se vários substratos proteicos (Tabela 4). As três preparações enzimáticas apresentaram alto nível de proteólise contra os substratos avaliados, apresentando atividades relativas superiores à da caseína, utilizada como padrão (100,0 
\%). É válido ressaltar a variação das especificidades de substratos das proteases em resposta aos diferentes resíduos agroindustriais utilizados para a produção das mesmas. O substrato que apresentou maiores índices de proteólise foi a hemoglobina de sangue bovino, com atividades relativas de 183,84, 147,06 e 186,81\% para as proteases PFT, PFS e PFA, respectivamente (Tabela 4). Os seguintes melhores substratos para hidrólise pela PFT foram: albumina de ovo $(137,37 \%)$ e as proteínas isolada e concentrada de soja (126,26 \%), enquanto para PFS e PFA, foram observadas maiores atividades relativas para os substratos gelatina e albumina do ovo (Tabela 4).

Tabela 4 - Especificidade de substrato das proteases de A. niger LBA 02 produzidos por fermentação em estado sólido utilizando farelo de trigo (PFT), farelo de soja (PFS) e farelo de algodão (PFA)

\begin{tabular}{lccc}
\hline \multirow{2}{*}{ Substratos } & \multicolumn{3}{c}{ Atividade relativa (\%) } \\
\cline { 2 - 4 } \multicolumn{1}{c}{ PFT } & PFS & PFA \\
\hline Caseína & $100,00 \pm 4,37^{\mathrm{a}}$ & $100,00 \pm 6,39^{\mathrm{a}}$ & $100,00 \pm 1,33^{\mathrm{a}}$ \\
Proteínas do soro de leite & $106,26 \pm 0,36^{\mathrm{b}}$ & $102,21 \pm 2,60^{\mathrm{a}}$ & $108,79 \pm 4,63^{\mathrm{b}, \mathrm{e}}$ \\
Proteína concentrada de soja & $126,26 \pm 9,08^{\mathrm{c}, \mathrm{d}, \mathrm{f}}$ & $105,88 \pm 6,11^{\mathrm{a}, \mathrm{b}}$ & $108,79 \pm 2,05^{\mathrm{b}}$ \\
Proteína isolada de soja & $126,26 \pm 2,79^{\mathrm{c}}$ & $101,47 \pm 3,39^{\mathrm{a}}$ & $106,59 \pm 3,66^{\mathrm{b}}$ \\
Hemoglobina de sangue bovino & $183,84 \pm 2,22^{\mathrm{e}}$ & $147,06 \pm 2,97^{\mathrm{c}}$ & $186,81 \pm 1,50^{\mathrm{d}}$ \\
Gelatina & $115,15 \pm 5,47^{\mathrm{d}}$ & $114,71 \pm 2,22^{\mathrm{b}}$ & $114,29 \pm 0,81^{\mathrm{e}}$ \\
Albumina de ovo & $137,37 \pm 3,42^{\mathrm{f}}$ & $112,50 \pm 1,77^{\mathrm{b}}$ & $127,47 \pm 2,12^{\mathrm{f}}$ \\
\hline
\end{tabular}

a, b, c Os resultados estão apresentados como média aritmética $(n=3) \pm$ desvio padrão e as letras diferentes indicam diferença estatística entre os valores $(p<0,05)$.

Os resultados para as atividades de coagulação do leite e de protease das enzimas produzidas por $A$. niger LBA 02 em comparação com outras preparações de proteases são apresentados na Tabela 5. O coalho comercial obtido a partir de A. niger apresentou relação entre atividade coagulante/protease superior às demais preparações avaliadas. As atividades de coagulação do leite das preparações enzimáticas de proteases de A. niger LBA 02 apresentaram diferentes valores em resposta a cada resíduo utilizado para a produção. A protease PFT mostrou relação atividade coagulante/protease $(15,24)$ superior às preparações comerciais de proteases, tais como Flavourzyme 500L $(0,13)$ e Alcalase $2.4 \mathrm{~L}(8,01)$.

Tabela 5 - Relação atividade coagulante do leite / protease das preparações enzimáticas de $A$. niger LBA 02 produzidas por fermentação em estado sólido utilizando farelo de trigo (PFT), farelo de soja (PFS) e farelo de algodão (PFA) e de outros coagulantes

\begin{tabular}{lccc}
\hline \multicolumn{1}{c}{ Enzimas } & $\begin{array}{c}\text { Atividade coagulante } \\
\left(\mathbf{U ~ m L ~}^{-1}\right)\end{array}$ & $\begin{array}{c}\text { Atividade de protease }^{\mathbf{1}} \\
\left(\mathbf{U ~ m L}^{-1}\right)\end{array}$ & $\begin{array}{c}\text { Relação } \\
\text { Coagulante/Protease })^{-1,22}\end{array}$ \\
\hline PFT & 22,22 & 1,46 & 15,24 \\
PFS & 0,56 & 1,44 & 0,38 \\
PFA & 5,80 & 0,92 & 6,28 \\
Flavourzyme 500L & $1.136,36$ & $8.513,00$ & 0,13 \\
Alcalase 2.4L & $111.627,91$ & $13.944,67$ & 8,01 \\
Coalho obtido de A. niger & $3.908,79$ & 26,46 & 147,72 \\
\hline
\end{tabular}

${ }^{1} \mathrm{~A}$ atividade de protease foi determinada utilizando azocaseína como substrato a $37,0^{\circ} \mathrm{C}$ e $\mathrm{pH} 6,5$. 


\section{CONCLUSÃO}

Os resultados obtidos no presente estudo mostraram que os resíduos agroindustriais farelos de trigo, soja e algodão permitiram a produção de proteases pela linhagem de $A$. niger LBA 02 por fermentação em estado sólido. A maior produção de protease foi observada quando utilizado o substrato farelo de trigo, atingindo $186,4 \mathrm{U} \mathrm{g}^{-1}$ após $96 \mathrm{~h}$ de fermentação. A caracterização bioquímica mostrou que as preparações enzimáticas apresentaram propriedades distintas em resposta a cada resíduo utilizado, com destaque para atividade coagulante do leite e especificidade de substrato. Os perfis de $\mathrm{pH}$ e temperatura ótima para atividade e estabilidade foram semelhantes para as proteases das preparações enzimáticas PFT, PFS e PFA.

\section{REFERÊNCIAS}

AHMED, I. A. M., MORISHIMA, I., BABIKER, E. E., MORI, N. Characterisation of partially purified milk-clotting enzyme from Solanum dubium Fresen seeds. Food Chemistry, v. 116, p. 395-400, 2009.

CASTRO, R. J. S., SATO, H. H. Synergistic effects of agroindustrial wastes on simultaneous production of protease and $\alpha$-amylase under solid state fermentation using a simplex centroid mixture design. Industrial Crops and Products, v. 49, p. 813-821, 2013.

CHARNEY, J., TOMARELLI, R. M. A colorimetric method for the determination of the proteolytic activity of duodenal juice. Journal of Biological Chemistry, v. 170, p. 501-505, 1947.

FAO. Disponível em: <http://faostat.fao.org/>. Acesso em: 01 março 2014.

FARNELl, E., ROUSSEAU, K., THORNTON, D. J., BOWYER, P., HERRICK, S. E. Expression and secretion of Aspergillus fumigatus proteases are regulated in response to different protein substrates. Fungal Biology, v. 116, p. 1003-1012, 2012.

KANEKAR, P. P., NILEGOANKAR, S. S., SARNAIK, S. S., KELKAR, A. S. Optimization of protease activity of alkaliphilic bacteria isolated from an alkaline lake in India. Bioresource Technology, v. 85, p. 87-93, 2002.

OSKOUIE, S. F. G., TABANDEH, F., YAKHCHALI, B., EFTEKHAR, F. Response surface optimization of medium composition for alkaline protease production by Bacillus clausii. Biochemical Engineering Journal, v. 39, p. 37-42, 2008.

PANDEY, A. Solid-state fermentation. Biochemical Engineering Journal, v. 13, n. 2, p. 81-84, 2003.

RAO, M. B., TANKSAlE, A. M., GHATGE, M. S., DESHPANDE, V. V. Molecular and biotechnological aspect of microbial proteases. Microbiology and Molecular Biology Reviews, v. 62, p. 597-635, 1998.

SPERANZA, P., CARVALHO, P. O., MACEDO, G. A. Effects of different solid state fermentation substrate on biochemical properties of cutinase from Fusarium sp. Journal of Molecular Catalysis B: Enzymatic, v. 72, p. 181-186, 2011. 